\title{
Remarkably Facile Preparation of Superhydrophobic Functionalized Bismuth Trioxide $\left(\mathrm{Bi}_{2} \mathrm{O}_{3}\right)$ Coatings
}

\author{
Tao-tao Liang ${ }^{1,2}$ and Xiao-gang Guo ${ }^{1,3,4, *}$ \\ 1 Faculty of Materials and Energy, Southwest University, Chongqing 400715, China \\ 2 Chongqing Key Laboratory of Inorganic Special Functional Materials, College of Chemistry and Chemical \\ Engineering, Yangtze Normal University, Chongqing 408100, China \\ 3 Green Intelligence Environmental School, Yangtze Normal University, Chongqing 408100, China \\ 4 Material Corrosion and Protection Key Laboratory of Sichuan Province, College of Chemistry and \\ Environmental Engineering, Institute of Functional Materials, Sichuan University of Science and \\ Engineering, Zigong 643000, China \\ * Correspondence: guoxiaogang0528@126.com
}

Received: 12 May 2019; Accepted: 29 May 2019; Published: 29 June 2019

\begin{abstract}
Herein, a novel superhydrophobic functionalized nano- $\mathrm{Bi}_{2} \mathrm{O}_{3}$ coating is designed and fabricated using electrophoretic assembly deposition (EAD) in the optimal suspension of polyethylene glycol, ethanol, acetylacetone, and surface functionalization. The small size (70 nm, nano-scale) of $\mathrm{Bi}_{2} \mathrm{O}_{3}$ particles and uniform distribution make the target film possessing a promising structure for realizing hydrophobic functionalization. Moreover, the hydrophobicity and stability results indicate that the product has a high-water contact angle (CA) of ca. $167^{\circ}$ and is kept almost stable after 180 days exposure in the natural environment. These findings will provide new insight into a better design of superhydrophobic functional coatings via this facile method, holding great promise for future various applications.
\end{abstract}

Keywords: nano- $\mathrm{Bi}_{2} \mathrm{O}_{3}$; electrophoretic assembly deposition; functionalization; hydrophobicity; stability

\section{Introduction}

Bismuth trioxide $\left(\mathrm{Bi}_{2} \mathrm{O}_{3}\right)$, possessing six polymorphic modification forms of $\alpha-\mathrm{Bi}_{2} \mathrm{O}_{3}, \beta-\mathrm{Bi}_{2} \mathrm{O}_{3}$, etc., is regarded as a promising semiconductor, which has attracted growing interests because of its narrower band gap of 2.5-2.8 eV (compared with traditional photocatalyst- $\mathrm{TiO}_{2}$ of $>3.0 \mathrm{eV}$ ) and thermal stability, high dielectric permittivity, and refractive index [1-4], resulting in $\mathrm{Bi}_{2} \mathrm{O}_{3}$ and its corresponding films' wide numerous technological application in fields of the fuel cell layer, catalysis, sensors, microelectronics, electro-optics, and so on [5-10].

Recently, various methods, such as magnetron sputtering and liquid deposition, have been used for synthesising $\mathrm{Bi}_{2} \mathrm{O}_{3}$, as described in literature [11-14]. For example, Qiu et al. proved that $\mathrm{Bi}_{2} \mathrm{O}_{3}$ films consisting of nanowires with an average diameter of $\sim 7 \mathrm{~nm}$ were fabricated using the Bi high temperature evaporation on an $\mathrm{Al}$ foil substrate, which wasfollowed by oxidative nucleation and growth at $350{ }^{\circ} \mathrm{C}$ [15]. The $\mathrm{Bi}_{2} \mathrm{O}_{3} / \mathrm{TiO}_{2}$ photocatalytic film coated on floated glass balls was used for efficient removal of an organic pollutant reported by Zou et al., by using a sol-gel method assisted with a double-solvent system [16]. Guan et al. designed a novel hetero-structured $\mathrm{Bi}_{2} \mathrm{O}_{3}-\mathrm{TiO}_{2}$ nanotube array composite film for photo-electrochemical cathode protection applications [17]. The thin films of bismuth oxide and yttrium-stabilized $\mathrm{Bi}_{2} \mathrm{O}_{3}$ were synthesized by a sol-gel/ink-jet printing method [18] and a pulsed laser deposition [19], respectively, which is complex in operation. However, the film-formation of $\mathrm{Bi}_{2} \mathrm{O}_{3}$ powders by a facile and low-cost technique is still a challenge.

In addition, the nano- $\mathrm{Bi}_{2} \mathrm{O}_{3}$ particles and their films are hydrophilic, leading to the destruction of structures in the humidity environment or under water conditions. Furthermore, instruction for 
designing the water-resistant $\mathrm{Bi}_{2} \mathrm{O}_{3}$ films are rarely reported. Thus, in this study, a novel superhydrophobic/functionalized $\mathrm{Bi}_{2} \mathrm{O}_{3}$ coating has been successfully prepared by a facile and low-cost technique using the electrophoretic assembly method (EAD) and surface modification, learning from the 'lotus effect' of surfaces capable of separating from water completely [20-22] and the facile and EAD conveniently film-forming design process based on low-cost equipment [23-26]. Furthermore, the microstructure and hydrophobic properties of the target film are investigated, which follows in detail.

\section{Experimental Section}

\subsection{Materials and Reagent}

Commercially available nano-bismuth trioxide (nano- $\mathrm{Bi}_{2} \mathrm{O}_{3}$ (III), CAS No. 1304-76-3) and other used reagents, including polyethylene glycol, ethanol, acetone, acetylacetone, polyethyleneimine and perfluorodecyltriethoxysilane were purchased from Aladdin Industrial Inc., Shanghai, China. The commercially available electrode materials of $\mathrm{Ti}$ and $\mathrm{Cu}$ sheets were used as received. Deionized water was used for all steps in this study.

\subsection{Methods}

To obtain stable suspension for a successful EAD process, $0.15 \mathrm{~g}$ nano- $\mathrm{Bi}_{2} \mathrm{O}_{3}$ aurantium powders were added into a $0.1 \mathrm{~L}$ mixture of polyethylene glycol, ethanol, and acetylacetone with a volume ratio of 0.01:0.45:0.45 in a glass beaker, which was moved into a water bath with an ultrasonic machine with $150 \mathrm{~W}$ (frequency of $30 \mathrm{kHz}$ ) for $0.5 \mathrm{~h}$, before adding a handful of polyethyleneimine as the modifier. The working and counter electrode was the Ti and $\mathrm{Cu}$ sheet, respectively, the distance between which was $0.01 \mathrm{~m}$. The pre-treatments of the electrode materials followed the steps as described below: (i) Grinding process by sandpapers, de-oiling process using a mixture of $\mathrm{NaOH}$ and $\mathrm{Na}_{2} \mathrm{SO}_{4}$ (mole ratio of 1:1), and cleaning process by deionized water and ethanol or acetone. (ii) The treated electrode materials were inserted vertically into an obtained stable suspension for EAD under different applied field strengths from 0 to $30 \mathrm{~V} / \mathrm{mm}$ at room temperature. The $\mathrm{Bi}_{2} \mathrm{O}_{3}$ films obtained after the EAD process underwent a functional modification process, similar to the surface treament technique reported in our previous study [24], and finally, they were changed into a novel functional superhydrophobic nano- $\mathrm{Bi}_{2} \mathrm{O}_{3}$ coating.

\subsection{Characterization}

The microscopic images of samples were analyzed by a field emission scanning electron microscope (FESEM, JSM-7800F, Japan). The canon camera (EOS 5D Mark IV, Japan) with lens (EF 24-70 mm f/4L IS USM) was used to investigate the macroscopic structures of samples and explore the hydrophobic immersion experiments of the products. The contact angle (CA) and water repellent stability of functional superhydrophobic nano- $\mathrm{Bi}_{2} \mathrm{O}_{3}$ films were characterized by an optical CA admeasuring apparatus (HARKE-SPCA, China).

\section{Results and Discussion}

\subsection{Microstructure and Surface Morphology}

It is universally acknowledged that a successful EAD mainly depends on a well-dispersed and stable suspension [27-29]. In this study, different kinds of suspensions were used to fabricate the functional superhydrophobic nano- $\mathrm{Bi}_{2} \mathrm{O}_{3}$ films, while controlling other fixed conditions, and the results in Table S1 in the Supplementary Materials show the combination of polyethylene glycol, ethanol, acetylacetone, and polyethyleneimine being the optimal suspension, for which the assembly efficiency of target films turned out be the highest. 
To explore the surface morphologies of superhydrophobic nano- $\mathrm{Bi}_{2} \mathrm{O}_{3}$ films, Figure 1 clearly displays the FESEM images with various magnifications of samples. As shown in Figure 1a, the target films consisted of a great deal of $\mathrm{Bi}_{2} \mathrm{O}_{3}$ particles with a relatively even distribution. After careful observation, there were lots of tiny crevices and bulges on the films, which largely contributed to realizing the design of the hydrophobic rough structures that was regarded as the key factor for preparing promising super-/hyrophobic materials, inspired by natural plants, for example, the lotus [30-32]. Moreover, Figure $1 \mathrm{~b}$ shows the higher magnification of target functional films, where the particles were still in nano scale (ca. $70 \mathrm{~nm}$ ) after the EAD process and other post-treatments, and the particle size distribution of nano- $\mathrm{Bi}_{2} \mathrm{O}_{3}$ is shown in Figure $\mathrm{S} 1$ in Supplementary Materials. In addition, lots of gaps existed among the nano- $\mathrm{Bi}_{2} \mathrm{O}_{3}$ particles, indicating the great superiority of the proposed EAD process under optimal suspension.

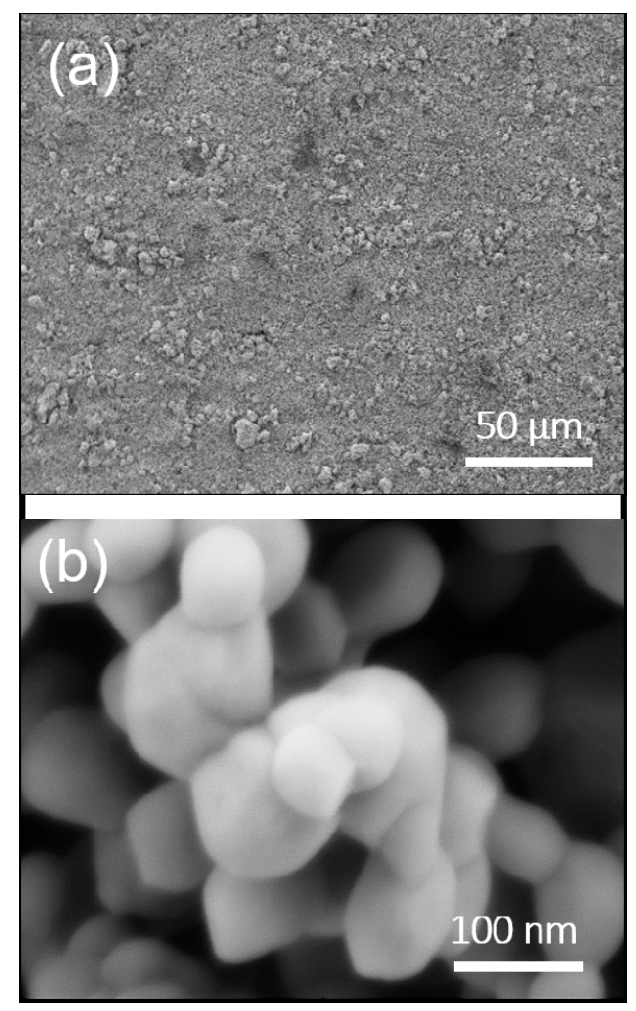

Figure 1. The typical FESEM images with low (a) and high (b) resolution ratios of obtained functional superhydrophobic nano- $\mathrm{Bi}_{2} \mathrm{O}_{3}$ films.

\subsection{EAD Dynamics}

Forming film efficiently is important, but realizing the controllability is even more essential. In this study, the EAD dynamics of nano- $\mathrm{Bi}_{2} \mathrm{O}_{3}$ particles in the optimal suspension were studied in detail. Figure 2 shows the relationship of the assembly efficiency $\left(\mathrm{mg} / \mathrm{cm}^{2}\right)$ of functional superhydrophobic nano- $\mathrm{Bi}_{2} \mathrm{O}_{3}$ films and the EAD, or assembly time ( $\mathrm{min}$ ). The assembly efficiency of the target film increased nearly linearly with the EAD time, increasing from 0 to $8 \mathrm{~min}$, and the rising tendency of the assembly efficiency decreased sharply as the EAD time continued to rise. It is worth mentioning that the relative weight gain of a product was not obvious after $18 \mathrm{~min}$ because of the gradual decrease of the concentration of particles. 


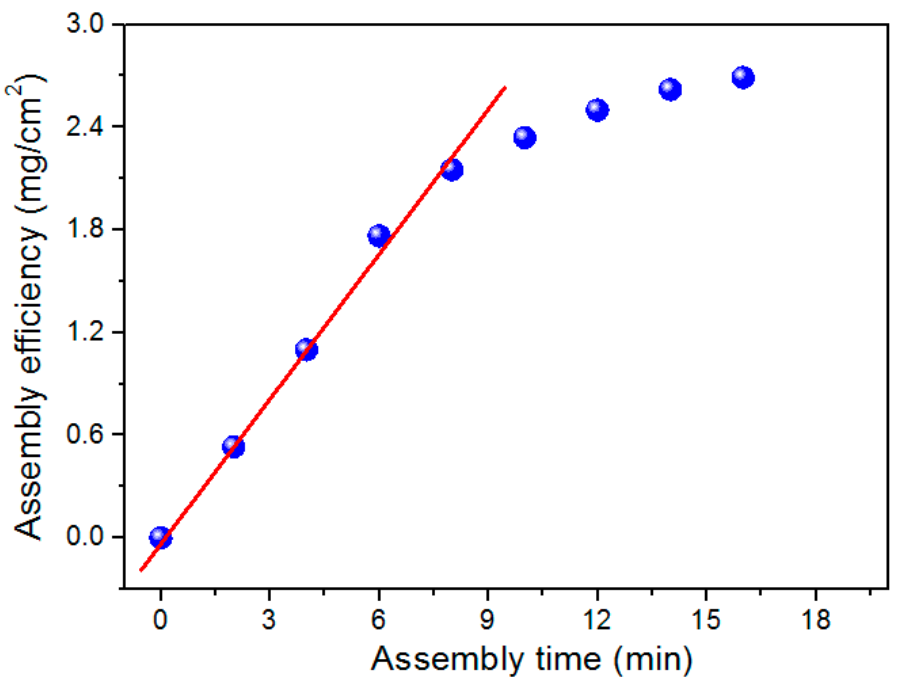

Figure 2. The assembly efficiency as a function of assembly time during the electrophoretic assembly deposition (EAD) process.

In addition, the effect of different applied field strengths on the assembly efficiency of the product is also analyzed in Figure 3. Interestingly, when the field strength was relatively low $(<15 \mathrm{~V} / \mathrm{mm})$, there also existed a similar linear correlation equation between the assembly efficiency and the field strength. The assembly efficiency increased at a much lower rate as the field strength exceeded $15 \mathrm{~V} / \mathrm{mm}$, which was caused by several reasons, including the more serious severe disturbance of suspension, the gradual increase of the resistance of electrodes, and the sedimentations of part particles [33]. These results provided a theoretical reference for a controllable assembly of nanoparticles by an optimal EAD process.

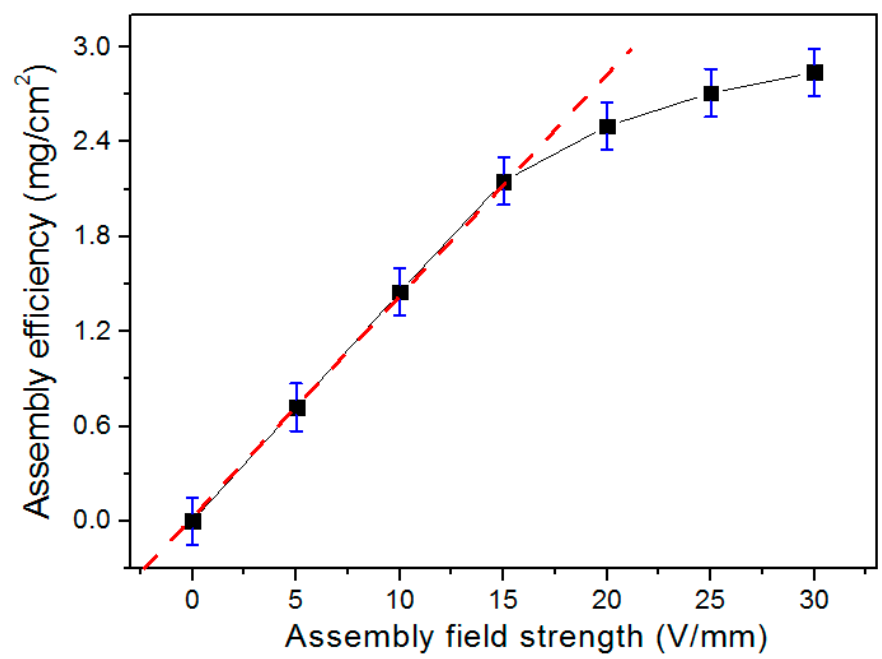

Figure 3. The assembly efficiency as a function of assembly field strength at room temperature.

\subsection{Hydrophobic Studies}

Firstly, the obtained functional novel nano- $\mathrm{Bi}_{2} \mathrm{O}_{3}$ film from scattered powder, was smooth and uniform, as shown in the Figure 4, where the color stays the same (yellow). The immersion test of product was then conducted to study its hydrophobicity. When the edge of target film slowly contacted the water, the surface of water was squeezed and the contacted part of water was pushed away, forming the interesting annular water lines (Figure 4) due to the strong water-repellency. After the immersion process, the samples under the water changed to a silvery surface, rather different from the other part of the product, which was caused by the light-reflections phenomenon of the air cushion 
layer on the surface of target functional films consisting of an abundance of captured air bubbles [34], further indicating the outstanding hydrophobicity. In addition, the CA of the product was ca. $168^{\circ}$ (see in the embedded image in Figure 5).

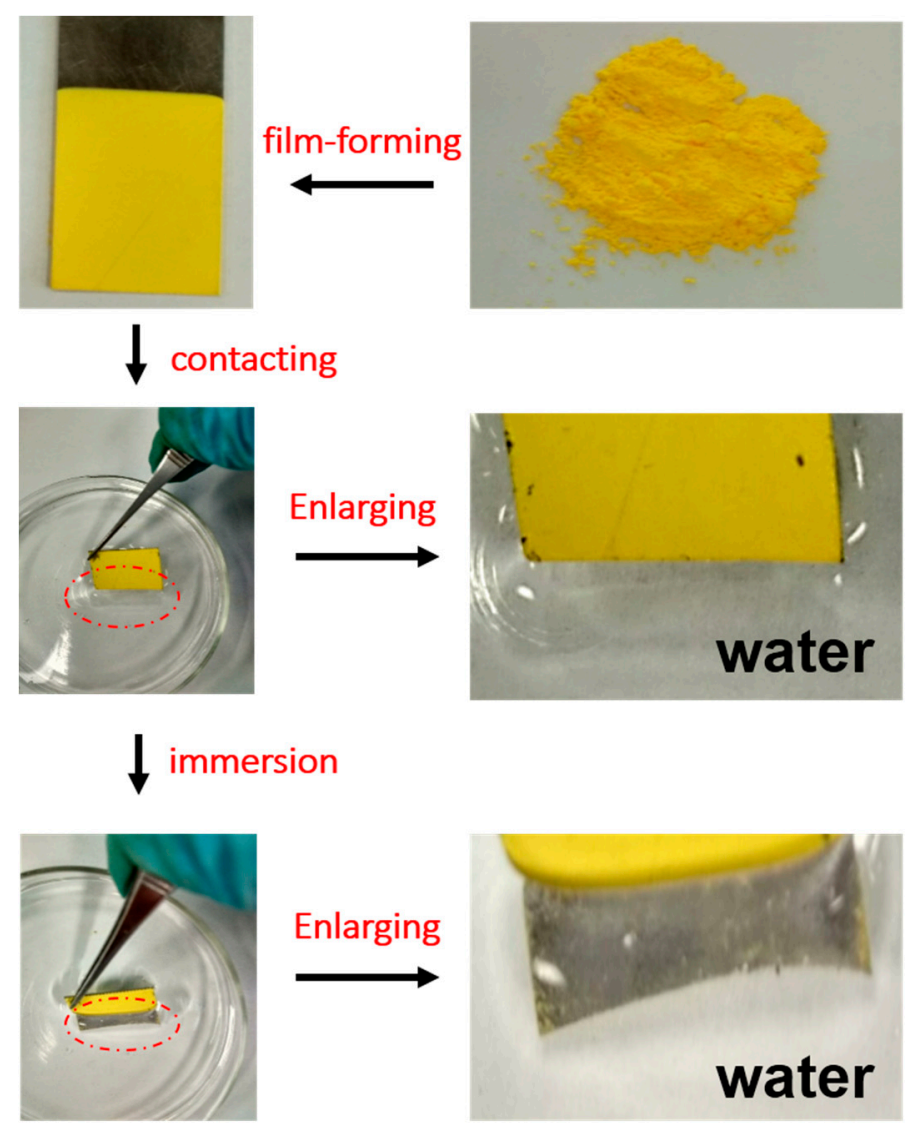

Figure 4. The film-forming process from nano-particles and the contacting and immersion process of the target hydrophobic nano- $\mathrm{Bi}_{2} \mathrm{O}_{3}$ films, with the corresponding enlarged "red circle" parts.

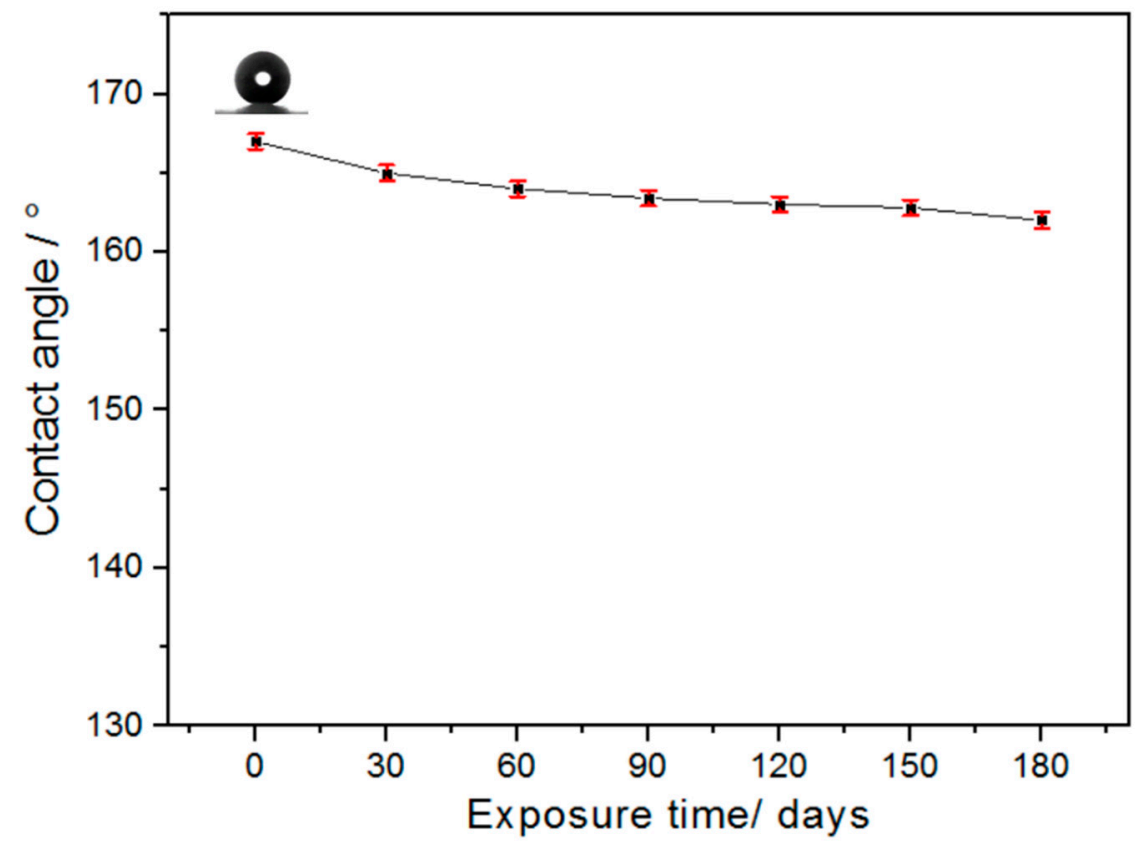

Figure 5. The contact angle (CA) of the target films as the function of different exposure time. 


\subsection{Stability Study}

To confirm the stability of the target functional nano- $\mathrm{Bi}_{2} \mathrm{O}_{3}$ films, the extra-long exposure experiments were conducted as follows. All samples were divided into seven groups (I-0 day, II-30 days, III-60 days, IV-90 days, V-120 days, VI-150 days, and VII-180 days), each going through a different exposure time. Figure 5 shows the relationship betweeen the $C A$ of $C$ with the fresh samples in group I. When the exposure time continued increasing, the CA of samples gradually decreased with an infinitesimal range, even for group VII after 180 days of exposure. The difference in value of CA between samples in group I and VII was only ca. $2^{\circ}$, which indicated that the product after a half-year exposure test still possessed great superhydrophobicity, furthermore demonstrating the outstanding stability of functional nano- $\mathrm{Bi}_{2} \mathrm{O}_{3}$ films with wide application in lots of domains.

\section{Conclusions}

In brief, the functional superhydrophobic nano- $\mathrm{Bi}_{2} \mathrm{O}_{3}$ film with high $\mathrm{CA}$ of $168^{\circ}$ and even distribution has been synthesized via a facile EAD and surface functionalization process at a mild condition. The target films turned out to be in nanoscale by the FESEM technique. In addition, the product showed outstanding superhydrophobic stability and kept a promising CA of ca. $166^{\circ}$, even after 180 days exposure. Thus, this work provides a new perspective for the fabrication of superhydrophobic oxide coatings with a wide potential application.

Supplementary Materials: The following are available online at http://www.mdpi.com/2076-3417/9/13/2653/s1, Figure S1: The particle size distribution of nano-Bi2O3; Table S1: Assembly efficiency comparison of different suspension agents.

Author Contributions: T.-t.L. and X.-g.G. designed the fabrication process of the superhydrophobic functionalized nano- $\mathrm{Bi}_{2} \mathrm{O}_{3}$ coatings, wrote the draft of the manuscript, and conducted the research. All authors contributed toward rechecking the manuscript and approved the final version.

Funding: This research was funded by the National Natural Science Foundation of China (21805014), the scientific and technological research program of Chongqing Municipal Education commission (KJQN201801424), the young scientist growth support project of Yangtze Normal University (2018QNRC10), and the opening project of material corrosion and protection key laboratory of the Sichuan province (2018CL19).

Acknowledgments: The authors acknowledge the financial support from the National Natural Science Foundation of China (research core funding No. 21805014), Chongqing Municipal Education commission (research core funding No. KJQN201801424), Yangtze Normal University (No. 2018QNRC10), and the opening project of material corrosion and protection key laboratory of the Sichuan province (research core funding No. 2018CL19).

Conflicts of Interest: The authors declare no conflict of interest.

\section{References}

1. Switzer, J.A.; Shunsky, M.G.; Bohannan, E.W. Electrodeposited ceramic single crystals. Science 1999, 284, $293-296$. [CrossRef] [PubMed]

2. Xu, H.H.; Hu, X.L.; Yang, H.L.; Sun, Y.M.; Hu, C.C.; Huang, Y.H. Flexible asymmetric micro-supercapacitors based on $\mathrm{Bi}_{2} \mathrm{O}_{3}$ and $\mathrm{MnO}_{2}$ nanoflowers: Larger areal mass promises higher energy density. Adv. Energy Mater. 2015, 5, 1401882-1401889. [CrossRef]

3. Khan, S.U.M.; Al-Shahry, M.; Ingler, W.B., Jr. Efficient Photochemical Water Splitting by a Chemically Modified n- $\mathrm{TiO}_{2}$. Science 2002, 297, 2243-2246. [CrossRef] [PubMed]

4. Qin, W.; Qi, J.; Wu, X.H. Photocatalytic property of $\mathrm{Cu}^{2+}$-doped $\mathrm{Bi}_{2} \mathrm{O}_{3}$ films under visible light prepared by the solegel method. Vacuum 2014, 107, 204-207. [CrossRef]

5. Liu, G.; Li, S.; Lu, Y.Y.; Zhang, J.; Feng, Z.C.; Li, C. Controllable synthesis of $\alpha-\mathrm{Bi}_{2} \mathrm{O}_{3}$ and $\gamma-\mathrm{Bi}_{2} \mathrm{O}_{3}$ with high photocatalytic activity by $\alpha-\mathrm{Bi}_{2} \mathrm{O}_{3} \rightarrow \gamma-\mathrm{Bi}_{2} \mathrm{O}_{3} \rightarrow \alpha-\mathrm{Bi}_{2} \mathrm{O}_{3}$ transformation in a facile precipitation method. J. Alloys Compd. 2016, 689, 787-799. [CrossRef]

6. Zhang, Y.Y.; Jung, J.I.; Luo, J. Thermal runaway, flash sintering and asymmetrical microstructural development of $\mathrm{ZnO}$ and $\mathrm{ZnO}-\mathrm{Bi}_{2} \mathrm{O}_{3}$ under direct currents. Acta Mater. 2015, 94, 87-100. [CrossRef]

7. Sopha, H.; Podzemna, V.; Hromadko, L.; Macak, J.M. Preparation of porcupine-like $\mathrm{Bi}_{2} \mathrm{O}_{3}$ needle bundles by anodic oxidation of bismuth. Electrochem. Commun. 2017, 84, 6-9. [CrossRef] 
8. Gao, X.M.; Shang, Y.Y.; Liu, L.B.; Fu, F. Chemisorption-enhanced photocatalytic nitrogen fixation via 2D ultrathin p-n heterojunction $\mathrm{AgCl} / \delta-\mathrm{Bi}_{2} \mathrm{O}_{3}$ nanosheets. J. Catal. 2019, 371, 71-80. [CrossRef]

9. Ke, J.; Liu, J.; Sun, H.Q.; Zhang, H.Y.; Duan, X.G.; Liang, P.; Li, X.Y.; Tade, M.O.; Liu, S.M.; Wang, S.B. Facile assembly of $\mathrm{Bi}_{2} \mathrm{O}_{3} / \mathrm{Bi}_{2} \mathrm{~S}_{3} / \mathrm{MoS}_{2} \mathrm{n}$-p heterojunction with layered n- $\mathrm{Bi}_{2} \mathrm{O}_{3}$ and $\mathrm{p}-\mathrm{MoS}_{2}$ for enhanced photocatalytic water oxidation and pollutant degradation. Appl. Catal. B Environ. 2017, 200, 47-55. [CrossRef]

10. Wang, W.Y.; Wang, X.W.; Cao, Z.Q.; Li, Q.C.; Feng, G.; Zhang, R.B. Enhancing photooxidative performance with $\mathrm{Bi}_{2} \mathrm{O}_{3}$ nanoparticle modified $\mathrm{BiVO}_{4}$ heterostructural flowers. J. Phys. Chem. C 2018, 122, 23582-23590. [CrossRef]

11. Coronado-Castañeda, R.R.S.; Maya-Treviño, M.L.; Garza-González, E.; Peral, J.; Villanueva-Rodríguez, M.; Hernández-Ramírez, A. Photocatalytic degradation and toxicity reduction of isoniazid using $\beta-\mathrm{Bi}_{2} \mathrm{O}_{3}$ in real wastewater. Catal. Today 2019, in press.

12. Que, Q.S.; Xing, Y.L.; He, Z.L.; Yang, Y.W.; Yin, X.T.; Que, W.X. $\mathrm{Bi}_{2} \mathrm{O}_{3} /$ Carbon quantum dots heterostructured photocatalysts with enhanced photocatalytic activity. Mater. Lett. 2017, 209, 220-223. [CrossRef]

13. Bai, J.W.; Li, Y.; Wei, P.K.; Liu, J.D.; Chen, W.; Liu, L. Enhancement of photocatalytic activity of $\mathrm{Bi}_{2} \mathrm{O}_{3}-\mathrm{BiOI}$ composite nanosheets through vacancy engineering. Small 2019, 1900020-1900028. [CrossRef]

14. Guo, X.G.; Liang, T.T.; Rager, M.; Cui, X. Low-temperature controlled synthesis of novel bismuth oxide $\left(\mathrm{Bi}_{2} \mathrm{O}_{3}\right)$ with microrods and microflowers with great photocatalytic activities. Mater. Lett. 2018, 228, 427-430. [CrossRef]

15. Qiu, Y.F.; Liu, D.F.; Yang, J.H.; Yang, S.H. Controlled synthesis of bismuth oxide nanowires by an oxidative metal vapor transport deposition technique. Adv. Mater. 2006, 18, 2604-2608. [CrossRef]

16. Zou, Q.; Li, H.; Yang, Y.P.; Miao, Y.C.; Huo, Y.N. $\mathrm{Bi}_{2} \mathrm{O}_{3} / \mathrm{TiO}_{2}$ photocatalytic film coated on floated glass balls for efficient removal of organic pollutant. Appl. Surf. Sci. 2019, 467-468, 354-360. [CrossRef]

17. Guan, Z.C.; Wang, H.P.; Wang, X.; Hu, J.; Du, R.G. Fabrication of heterostructured $\beta-\mathrm{Bi}_{2} \mathrm{O}_{3}-\mathrm{TiO}_{2}$ nanotube array composite film for photoelectrochemical cathodic protection applications. Corros. Sci. 2018, 136, 60-69. [CrossRef]

18. Luévano-Hipólito, E.; Torres-Martínez, L.M.; Triana, C.; Lee, S.W. Ink-jet $\mathrm{Bi}_{2} \mathrm{O}_{3}$ films and powders for $\mathrm{CO}_{2}$ capture and self-cleaning applications. Thin Solid Films 2019, 677, 83-89. [CrossRef]

19. Jeong, S.J.; Kwak, N.W.; Byeon, P.; Chung, S.Y.; Jung, W.C. Conductive nature of grain boundaries in nanocrystalline stabilized $\mathrm{Bi}_{2} \mathrm{O}_{3}$ thin-film electrolyte. ACS Appl. Mater. Interfaces 2018, 10, 6269-6275. [CrossRef]

20. Meng, Y.; Wang, M.J.; Tang, M.F.; Hong, G.H.; Gao, J.M.; Chen, Y. Preparation of robust superhydrophobic halloysite clay nanotubes via mussel-inspired surface modification. Appl. Sci. 2017, 7, 1129. [CrossRef]

21. Erbil, H.Y.; Demirel, A.L.; Avci, Y.; Mert, O. Transformation of a simple plastic into a superhydrophobic surface. Science 2003, 299, 1377-1380. [CrossRef] [PubMed]

22. Mohammadi, M.; Tembely, M.; Dolatabadi, A. Supercooled water droplet impacting superhydrophobic surfaces in the presence of cold air flow. Appl. Sci. 2017, 7, 130. [CrossRef]

23. Ravi, V.K.; Scheidt, R.A.; DuBose, J.; Kamat, P.V. Hierarchical arrays of cesium lead halide perovskite nanocrystals through electrophoretic deposition. J. Am. Chem. Soc. 2018, 140, 8887-8894. [CrossRef] [PubMed]

24. Guo, X.G.; Li, X.M.; Wei, Z.B.; Li, X.L.; Niu, L.D. Rapid fabrication and characterization of superhydrophobic tri-dimensional Ni/Al coatings. Appl. Surf. Sci. 2016, 387, 8-15. [CrossRef]

25. Fritz, P.A.; Lange, S.C.; Giesbers, M.; Zuilhof, H.; Boom, R.M.; Schroen, C.G.P.H. Simultaneous silicon oxide growth and electrophoretic deposition of graphene oxide. Langmuir 2019, 35, 3717-3723. [CrossRef] [PubMed]

26. Guo, X.G.; Lai, C.; Jiang, X.; Mi, W.H.; Yin, Y.J.; Li, X.M.; Shu, Y.J. Remarkably facile fabrication of extremely superhydrophobic high-energy binary composite with ultralong lifespan. Chem. Eng. J. 2018, 335, 843-854. [CrossRef]

27. Singh, B.P.; Menchavez, R.; Takai, C.; Fuji, M.; Takahashi, M. Stability of dispersions of colloidal alumina particles in aqueous suspensions. J. Colloid Interface. Sci. 2015, 291, 181-186. [CrossRef] [PubMed]

28. Guo, X.G.; Li, X.M.; Li, H.R.; Zhang, D.X.; Lai, C.; Li, W.L. A comprehensive investigation on the electrophoretic deposition (EPD) of nano-Al/Ni energetic composite coatings for the combustion application. Surf. Coat. Technol. 2015, 265, 83-91. [CrossRef] 
29. Fang, J.; Shan, X.-Q.; Wen, B.; Lin, J.-M.; Owens, G. Stability of titania nanoparticles in soil suspensions and transport in saturated homogeneous soil columns. Environ. Pollut. 2009, 157, 1101-1109. [CrossRef] [PubMed]

30. Guo, X.G.; Li, X.M.; Lai, C.; Jiang, X.; Li, X.L.; Shu, Y.J. Facile approach to the green synthesis of novel ternary composites with excellent superhydrophobic and thermal stability property: An expanding horizon. Chem. Eng. J. 2017, 309, 240-248. [CrossRef]

31. Lu, Y.; Sathasivam, S.; Song, J.L.; Crick, C.R.; Carmalt, C.J.; Parkldn, I.P. Robust self-cleaning surfaces that function when exposed to either air or oil. Science 2015, 347, 1132-1135. [CrossRef] [PubMed]

32. Deng, X.; Mammen, L.; Butt, H.J.; Vollmer, D. Candle soot as a template for a transparent robust superamphiphobic coating. Science 2012, 335, 67-70. [CrossRef] [PubMed]

33. Wang, Y.C.; Leu, I.C.; Hou, M.H. Kinetics of electrophoretic deposition for nanocrystalline zinc oxide coatings. J. Am. Ceram. Soc. 2004, 87, 84-88. [CrossRef]

34. Larmour, I.A.; Bell, S.E.J.; Saunders, G.C. Remarkably simple fabrication of superhydrophobic surfaces using electroless galvanic deposition. Angew. Chem. Int. Ed. 2007, 119, 1740-1742. [CrossRef]

(C) 2019 by the authors. Licensee MDPI, Basel, Switzerland. This article is an open access article distributed under the terms and conditions of the Creative Commons Attribution (CC BY) license (http://creativecommons.org/licenses/by/4.0/). 